\title{
A tomato bZIP transcription factor, SIAREB, is involved in water deficit and salt stress response
}

\author{
Tsai-Hung Hsieh $\cdot$ Chia-Wen Li • Ruey-Chih Su • \\ Chiu-Ping Cheng $\cdot$ Sanjaya $\cdot$ Yi-Chien Tsai $\cdot$ \\ Ming-Tsair Chan
}

Received: 6 November 2009/Accepted: 10 March 2010/Published online: 1 April 2010

(c) Springer-Verlag 2010

\begin{abstract}
Abiotic stresses such as cold, water deficit, and salt stresses severely reduce crop productivity. Tomato (Solanum lycopersicum) is an important economic crop; however, not much is known about its stress responses. To gain insight into stress-responsive gene regulation in tomato plants, we identified transcription factors from a tomato cDNA microarray. An ABA-responsive element binding protein (AREB) was identified and named SlAREB. In tomato protoplasts, SIAREB transiently transactivated luciferase reporter gene expression driven by AtRD29A (responsive to dehydration) and SILAP (leucine aminopeptidase) promoters with exogenous ABA application, which was suppressed by the kinase inhibitor staurosporine, indicating that an ABA-dependent post-translational modification is required for the transactivation ability of SIAREB protein. Electrophoretic mobility shift assays
\end{abstract}

T.-H. Hsieh, C. -W. Li and R.-C. Su contributed equally to this work.

Electronic supplementary material The online version of this article (doi:10.1007/s00425-010-1147-4) contains supplementary material, which is available to authorized users.

T.-H. Hsieh · Sanjaya · Y.-C. Tsai

Agricultural Biotechnology Research Center, Academia Sinica,

Taipei 115, Taiwan

C.-W. Li · M.-T. Chan $(\bowtie)$

Academia Sinica, Biotechnology Center in Southern Taiwan,

Tainan 74146, Taiwan

e-mail: mbmtchan@gate.sinica.edu.tw

R.-C. Su

Department of Life Science, Fu Jen Catholic University,

Taipei 24205, Taiwan

C.-P. Cheng

Institute of Plant Biology, National Taiwan University,

Taipei 106, Taiwan showed that the recombinant DNA-binding domain of SIAREB protein is able to bind AtRD29A and SILAP promoter regions. Constitutively expressed SIAREB increased tolerance to water deficit and high salinity stresses in both Arabidopsis and tomato plants, which maintained PSII and membrane integrities as well as water content in plant bodies. Overproduction of SlAREB in Arabidopsis thaliana and tomato plants regulated stress-related genes AtRD29A, AtCOR47, and SlCI7-like dehydrin under ABA and abiotic stress treatments. Taken together, these results show that $S I A R E B$ functions to regulate some stress-responsive genes and that its overproduction improves plant tolerance to water deficit and salt stress.

Keywords ABA-responsive element binding protein . Abscisic acid · Salinity $\cdot$ Water deficit

\author{
Abbreviations \\ ABA Abscisic acid \\ ABRE ABA-responsive element \\ AREB ABA-responsive element binding protein \\ Present Address: \\ T.-H. Hsieh \\ Institute of Plant and Microbial Biology, \\ Academia Sinica, Taipei 115, Taiwan \\ Sanjaya \\ Department of Biochemistry and Molecular Biology, \\ Great Lakes Bioenergy Research Center, MSU, \\ East Lansing, MI 48824, USA \\ Y.-C. Tsai \\ Genomics Research Center, Academia Sinica, \\ Taipei 115, Taiwan
}


SIAREB Solanum lycopersicum ABA-responsive element binding protein

RD29A Responsive to dehydration 29A

LAP Leucine aminopeptidase

CI7 Cold-induced 7

\section{Introduction}

Plant growth and productivity are severely affected by various abiotic stresses including drought, salinity, extreme temperature, and heavy metals. Being sessile in nature, plants respond and adapt to these environmental stresses by altering the biochemical, physiological, and transcriptional activation of several stress-responsive genes (Shinozaki and Yamaguchi-Shinozaki 2000). Thus, increased information about stress-related gene regulation at the transcriptome level will greatly facilitate target gene selection and engineering of stress-tolerant transgenic plants (Shinozaki and Yamaguchi-Shinozaki 2000; Chinnusamy et al. 2004). Over the past few years, cDNA and oligonucleotide microarrays (e.g., Affymetrix GeneChip microarrays) have been utilized as a high-throughput detection system to rapidly identify stress-regulated genes from global expression profiles (Zhu 2001; Seki et al. 2004; Rensink and Buell 2005). Gene expression profiles of rice (Oryza sativa), barley (Hordeum vulgare), and yeast (Saccharomyces cerevisiae) under saline stress have successfully been obtained by microarray analyses demonstrating the feasibility of this approach (Kawasaki et al. 2001; Yale and Bohnert 2001; Oztur et al. 2002). Similarly, transcriptome changes in Arabidopsis and rice subjected to cold, drought, or saline conditions have been investigated by the use of DNA microarrays (Rabbani et al. 2003; Takahashi et al. 2004). Although significant progress has been made in recent years, the available information about mechanisms of plant responses to abiotic stresses in tomato plants is still scarce in comparison with Arabidopsis. Tomato is a member of the Solanaceae family, economically the third most important commercial crop family, and has long been used as a model plant in fruit ripening, disease response, genetics, and whole genome sequence studies (Mueller et al. 2005). Global expression profiling will facilitate understanding of the transcriptional regulation of stress-responsive genes and highlight useful genes for improving stress tolerance in tomato.

Plants encode a large number of transcription factors which are classified by their DNA-binding domains (Stracke et al. 2001). There is growing evidence that these transcription factors regulate diverse biological processes such as pathogen defense, light and stress signaling, seed maturation, and flower development (Jakoby et al. 2002). The levels of endogenous abscisic acid (ABA) increase significantly in many plants under abiotic stresses. In one of the ABA-dependent pathways, water-stress-inducible genes, such as AtRD29A and AtCOR47, contain potential ABREs (ABA-responsive elements, PyACGTGG) in their promoter regions. Arabidopsis ABF2 (ABRE-binding factor 2)/AREB1 (ABA-response $e$ lement $b$ inding factor 1 ) (At1g45249), ABF4/AREB2 (At3g19290), and AREB3 (At3g56850) have been identified by a yeast one-hybrid system to interact with ABREs in vitro (Uno et al. 2000). Expressions of AREB1, AREB2, and AREB3 genes are induced by drought, salt, and ABA treatments in vegetative tissues (Uno et al. 2000). In Arabidopsis protoplasts, both AREB1 and AREB2 transiently transactivate ABREcontaining promoters in an ABA-dependent manner (Uno et al. 2000). Furthermore, ABA-induced phosphorylations of AREBs through SnRKs (SNF1-related protein kinases) are important for activation of ABA-responsive genes by AREBs (Yoshida et al. 2002; Furihata et al. 2006; Fujii and Zhu 2009). It has been shown that AREB1 functions as a prerequisite for seedling growth regulation and glucose response, conferring tolerance to multiple stresses, including drought, salt, heat, and oxidative stresses, suggesting that AREB1 plays a vital role in adaptation to these stresses (Kim et al. 2004; Fujita et al. 2005). In comparison with AREB1, overproduction of ABF3 and AREB2 result in enhanced $\mathrm{ABA}$, salt and glucose sensitivities, and drought tolerance, demonstrating that $\mathrm{ABF} 3$ and AREB2 play distinct roles in $\mathrm{ABA}$ and stress responses under specific conditions (Kim et al. 2004). In addition, other homologs of AREB have been identified: TRABI (transcription factor responsible for $A B A$ regulation 1 ) in rice (Oryza sativa) and HvABI5 in barley (Hordeum vulgare), which are both involved in ABA-mediated gene regulation; and Wabi5 in wheat (Triticum aestivum), which confers tolerance to freezing, osmotic, and salt stresses in transgenic tobacco plants (Hobo et al. 1999; Casaretto and Ho 2005; Kobayashi et al. 2008). In Arabidopsis, functional characterization of AREB1 and AREB2 under ABA, drought, and high salinity stresses have been well demonstrated (Uno et al. 2000; Narusaka et al. 2003); however, the function of tomato AREB and its regulation at the transcriptional level in tomato plants under stress conditions are not clearly understood.

Plant physiologists are defining tolerance to drought as the ability to overcome a low tissue water potential during desiccation (Chaves et al. 2003). Plants use more than one drought-resistance strategy at a time to resist dehydration stress, including drought escape via a short life cycle or developmental plasticity, drought avoidance, and drought tolerance. Drought avoidance refers to adaptive mechanisms that aim to protect tissue by saving water (e.g., by 
reduction of transpiration through stomatal closure, reduced leaf size, altered leaf structure, leaf abscission, and thick cuticles) and reaching more water (e.g., by forming deep wide-spreading root systems). The mechanisms of drought tolerance are maintenance of turgor through osmotic adjustment (solute and/or osmolyte accumulation), increased cell wall rigidity, and reduced cell size. In this article, we will use the term tolerance to refer to plants that seem unaffected by the abiotic stress we apply.

In this study, we identified an AREB-like transcription factor (accession number: AY530758), SlAREB, by use of a tomato cDNA microarray (Liu et al. 2006). SlAREB showed temporal and spatial abiotic stress response and is involved in an ABA-dependent stress signaling pathway in tomato. Overexpression of SlAREB in transgenic Arabidopsis and tomato plants significantly increases tolerance to water deficit and salt stresses, as well as regulation of stress-related genes under ABA and stress treatments.

\section{Materials and methods}

Plant growth and stress treatments

Seeds of Solanum lycopersicum (L.) Miller cv. CL591593D $4-1-0-3$, were kindly provided by the World Vegetable Center (AVRDC, Shanhua, Taiwan). Wild-type plants were grown in controlled environment chambers at $24^{\circ} \mathrm{C}$, $50 \%$ relative humidity, with a 16-h photoperiod (about $120 \mu \mathrm{mol} \mathrm{m} \mathrm{m}^{-2}$ ).

For the investigation of SlAREB expression profiles, 6-week-old wild-type tomato plants, cultured in a hydroponic system, were transferred to pre-chilled Hoagland's solution and incubated at $4^{\circ} \mathrm{C}$ for chilling treatment, air-dried in the growth chamber after removal from Hoagland's solution for water deficit treatment, or incubated at $200 \mathrm{mM} \mathrm{NaCl}$ in Hoagland's solution for salt treatment. The incubation time of each treatment was 0.5 , $1,2,12$, and $24 \mathrm{~h}$, respectively, after which leaves and roots were collected separately.

RNA isolation and Northern-blot analysis

Total RNA was isolated from normal-growth and stresstreated wild-type and transgenic plants using a Trizol reagent (Invitrogen, Carlsbad, CA, USA), separated on 1\% agarose gel, and transferred to nylon membrane. Each gene tested was labeled with $\left[\alpha_{-}{ }^{32} \mathrm{P}\right]$ dCTP using a random labeling method (Smith 1996). The RNA blot membranes were hybridized with cDNA fragments of genes, including SIAREB (EST clone LEPSR08G09, GenBank accession number DV105299), SlCI7-like dehydrin (EST clone cLEX8A20, AW220124), and ubiquitin 3 (X58253).
Segments of four leaves from each of two individual plants were collected and used for total RNA isolation. Each experiment was performed in triplicate.

\section{Promoter isolation}

Genomic DNA was extracted from leaves of wild-type tomato plants (Murray and Thompson 1980) and used for GenomeWalker reactions, which were carried out as described by the manufacturer (BD GenomeWalker Universal Kit, Clontech, Mountain View, CA, USA). In addition to genome walking, inverse PCR was used to extend the tomato SlCI7-like dehydrin promoter sequence by use of specific primers (CI7-R1, 5'-CTAGAGCTGC TA TTTGATCGATGAAGT-3' and CI7-R2, 5' -TCCTCCTCC TTGGGTTCCAC TTCTTCA- $3^{\prime}$ designed from EST clone cLEX8A20). The following amplification program was used for the first PCR of genome walking: 1 cycle of $95^{\circ} \mathrm{C}$ for $1 \mathrm{~min}, 7$ cycles of $94^{\circ} \mathrm{C}$ for $25 \mathrm{~s}$ and $72^{\circ} \mathrm{C}$ for $3 \mathrm{~min}, 32$ cycles of $94^{\circ} \mathrm{C}$ for $25 \mathrm{~s}$ and $67^{\circ} \mathrm{C}$ for $3 \mathrm{~min}$, then 1 cycle of $67^{\circ} \mathrm{C}$ for $7 \mathrm{~min}$. The program for the second PCR of genome walking was 1 cycle of $95^{\circ} \mathrm{C}$ for $1 \mathrm{~min}, 5$ cycles of $94^{\circ} \mathrm{C}$ for $25 \mathrm{~s}$ and $72^{\circ} \mathrm{C}$ for $3 \mathrm{~min}, 25$ cycles of $94^{\circ} \mathrm{C}$ for $25 \mathrm{~s}$ and $67^{\circ} \mathrm{C}$ for $3 \mathrm{~min}$, then 1 cycle of $67^{\circ} \mathrm{C}$ for $7 \mathrm{~min}$. The PCR products were subsequently ligated to the pGEMT easy vector (Promega, Madison, MI, USA) for DNA sequencing.

\section{Transient expression analysis}

To construct the effector plasmid, the luciferase gene (LUC) of pJD301 (Luehrsen et al. 1992) was replaced by full-length cDNA of SlAREB at SalI and SacI sites. Reporter plasmids were constructed by replacing the CaMV $35 S$ promoter of pJD301 with either the AtRD29A promoter (TAC clone: K24M7, accession number: AB019226, from 12,015 to 12,649), the tomato CI7-like dehydrin promoter (both at HindIII and SalI sites), or the SILAP promoter (accession number: Y08305) at BamHI and SalI sites. All plasmids used for transient expression analysis were purified by the Qiagen Plasmid Mega kit (Qiagen, Hilden, Germany) and confirmed by DNA sequencing. Five-day-old wild-type tomato suspension cells were harvested and resuspended in enzyme solution [1/4 MS (Murashige and Skoog 1962; pH 5.8; Duchefa, Haarlem, The Netherlands), MS vitamins, 3\% sucrose, $0.4 \mathrm{M}$ mannitol 2\% cellulase RS (Yakult Honsha Co., Tokyo, Japan), 1\% macerozyme R-10 (Yakult Honsha)], and then incubated for $4 \mathrm{~h}$ at $24^{\circ} \mathrm{C}$ in the dark. The cell pellets were collected by centrifugation at $100 \mathrm{~g}$ for $5 \mathrm{~min}$, and then washed twice with WI solution (0.5 M mannitol, $4 \mathrm{mM}$ Mes, $\mathrm{pH} 5.7,20 \mathrm{mM} \mathrm{KCl}$ ). The cell pellets were gently resuspended with $20 \%$ sucrose and centrifuged at 
$800 \mathrm{~g}$ for $5 \mathrm{~min}$. After centrifugation, protoplasts were collected and washed twice with WI solution; the resulting protoplasts were counted with a hemocytometer. $10 \mu \mathrm{g}$ plasmid DNA of each construction was electroporated into protoplasts using the BTX electroporator $(200 \mathrm{~V}, 13 \Omega$, $1,000 \mu \mathrm{F})$. Samples were then incubated with $10 \mu \mathrm{M}$ ABA (Sigma, St Louis, MO, USA) or $0.5 \mu \mathrm{M}$ staurosporine (Merck-Calbiochem, Darmstadt, Germany) for 20 or $40 \mathrm{~h}$ at $24^{\circ} \mathrm{C}$.

\section{Electrophoretic mobility shift assays (EMSA)}

The putative DNA-binding domain of SIAREB (nucleotide sequence from 1,084 to $1,278 \mathrm{bp}$ ) was cloned into pET32a bacterial expression vectors (Novagen, Darmstadt, Germany) using EcoRV and HindIII sites to produce Histagged fusion proteins. Recombinant proteins were purified using a nickel-nitrilotriacetic acid agarose column (Promega). $4 \mu \mathrm{g}$ of recombinant proteins were used in electrophoretic mobility shift assays along with radiolabeled fragments of the SILAP or AtRD29A promoters. Doublestranded oligonucleotide probes were amplified by PCR using primers (5'-TGTAGGGTATCACGTAGGAC- $\left.3^{\prime}\right)$ and $\left(5^{\prime}\right.$-GCATGTCAACACGTTTTACT- $\left.3^{\prime}\right)$ for the SILAP promoter and (5'-ACAGACGCTTCATACGTGTC- $\left.3^{\prime}\right)$ and $\left(5^{\prime}\right.$-AAACCCTTTATTCCTGATGA- $\left.3^{\prime}\right)$ for AtRD29A promoter. The purified PCR products were radiolabeled with $\left[\gamma^{32} \mathrm{P}\right]$ ATP by $\mathrm{T} 4$ polynucleotide kinase (New England Biolabs, Ipswich, MA, USA). For binding reactions, recombinant proteins ( $4 \mu \mathrm{g}$ each) were incubated for $30 \mathrm{~min}$ at room temperature with $0.5 \mathrm{ng}$ of radiolabeled probe and $1 \mu \mathrm{g}$ of poly $(\mathrm{dI}-\mathrm{dC})$ in $30 \mu \mathrm{l}$ buffer containing $10 \mathrm{mM}$ Tris- $\mathrm{HCl}$ (pH 7.6), $50 \mathrm{mM} \mathrm{KCl}, 0.5 \mathrm{mM}$ EDTA, $10 \%$ (v/v) glycerol, and $1 \mathrm{mM}$ DTT. Competitors were added in a 300- or 3,000-fold molar excess. All reaction mixtures were resolved on a $4 \%$ polyacrylamide gel $(120 \mathrm{~V}$ for $2 \mathrm{~h}$ ) in $0.5 \times$ TBE buffer $(45 \mathrm{mM}$ Tris, $45 \mathrm{mM}$ boric acid, and $1 \mathrm{mM}$ EDTA).

Generation of transgenic Arabidopsis and tomato plants

The whole SIAREB coding region was cloned into pJD301 by removing a LUC at the SalI and SacI sites. The fragment containing CaMV $35 S$ promoter, a SIAREB cDNA open reading frame from start to stop codon and a nos terminator was cloned into pCAMBIA2301 and pCAMBIA1301 (Center for Application of Molecular Biology of International Agriculture, Black Mountain, Australia), and then transformed into Agrobacterium tumefaciens strain GV3101 and EHA105 cells by electroporation for Arabidopsis and tomato transformation, respectively. Transformation of Arabidopsis thaliana (Columbia) was performed by flower dipping. Tomato transformation procedures were conducted as described previously (Hsieh et al. 2002). Twenty-one and 20 independent lines of Arabisopsis and tomato transgenic plants were obtained, respectively. For each, three $T_{2}$ homozygous lines with high-level expression of transgene were chosen for further analyses.

Molecular characterization of transgenic Arabidopsis and tomato plants

Transgenic Arabidopsis and tomato plants were selected on $100 \mathrm{mg} / \mathrm{l}$ kanamycin (pCAMBIA2301/35S::SIAREB) or $20 \mathrm{mg} / 1$ hygromycin (pCAMBIA1301/35S::SlAREB). Total RNA extracted from leaves of transgenic and untransformed plants were used for Northern-blot hybridization as previously described. The following probes were used for hybridization: Arabidopsis COR47 (At1g20440), tomato SIAREB, SlCI7-like dehydrin, and ubiquitin 3 (UBI3). These cDNA fragments were labeled with $\left[\alpha_{-}{ }^{32} \mathrm{P}\right]$ dCTP using the random primer method (Smith 1996).

Water deficit and salt treatments of Arabidopsis and tomato plants

For ABA or PEG treatment, seeds of three independent lines of SIAREB $\mathrm{T}_{3}$ transgenic and wild-type Arabidopsis (20 plants each) were sowed onto $100-\mu \mathrm{m}$ nylon mesh supports on MS agar plates. Three-week-old Arabidopsis seedlings with mesh were transferred to liquid 1/2 MS medium with $50 \mu \mathrm{M}$ ABA or $30 \%$ PEG8000 for 0,5 and $8 \mathrm{~h}$, and then collected for Northern-blot analysis.

In Arabidopsis, for water deficit treatment, 20 seedlings each of 1-week-old wild-type and three $\mathrm{T}_{3}$ transgenic Arabidopsis lines were grown in the same pot ( 3 pots per experiments; 3 repeats) with watering every 2 days for 3 weeks followed by no watering for 2 weeks. For salt treatment, 12 seedlings each of 1-week-old wild-type and three transgenic Arabidopsis lines were grown in the same pot (3 pots per experiments; 3 repeats) with regular watering every 2 days for 3 weeks, followed by watering every 2 days with a $150 \mathrm{mM} \mathrm{NaCl}$ solution for 2 weeks. Photographs were taken after water deficit or salt treatment for 2 weeks.

In tomato, one seedling each of three $\mathrm{T}_{2}$ transgenic and wild-type plants was planted into the same pot. Tomatoes of three pots per experiment were subjected to abiotic stresses such as water deficit and salt stress. All the experiments were performed at least in triplicate. For water deficit treatment, wild-type and transgenic tomato were grown in the same pot under $15 \mathrm{~h}$ illumination at $22^{\circ} \mathrm{C}$ and $35 \%$ relative humidity for 3 weeks with watering every 2 days, and then subjected to drought by withholding irrigation for 3 weeks. During the water deficit treatment, we 
measured Fv/Fm values (Hsieh et al. 2002) and water content of leaves at day $0,7,14$, and 21 . In addition, we measured water content of roots at day 0 and sacrificed roots at day 21 for calculation of water content. For salt treatment, 1-week-old wild-type and transgenic tomatoes were planted into soil in the same pot and grown for one week. Plants were then watered every 2 days with a $200 \mathrm{mM} \mathrm{NaCl}$ solution for 4 weeks. At the end of the treatment, photographs were taken and the MDA content (Sanjaya et al. 2008) and Fv/Fm values were measured. Independent experiments were performed in triplicate with three pots each.

\section{Results}

Characterization and identification of a bZIP transcription factor that responds to abiotic stresses in tomato plants

To study stress-related gene regulation at the transcriptional level in tomato, we screened for genes involved in abiotic stress response by using a homemade cDNA microarray as described by Liu et al. (2006). Wild-type tomato plants were grown under conditions of low temperature, air drying, or high salinity for different periods, and leaves and roots were collected separately to prepare hybridization probes. Hybridization results showed that some transcription factors showed up-regulation under various abiotic stresses in different tissues (data not shown). In this study, we characterized the cDNA clone LEPSR08G09 (accession number DV105299), which encodes a bZIP protein that was transiently upregulated by air drying (drought treatment) and salt treatments in both leaves and roots (Fig. 1). A BLAST search of the Arabidopsis genome database revealed that LEPSR08G09 shares a high level of similarity with Arabidopsis AREBI (AtAREB1, At1g45249); therefore it was named SlAREB. AtAREB 1 has previously been shown to respond to chilling, air drying, or salt stresses (Sakamoto et al. 2000; Uno et al. 2000; Kreps et al. 2002; Mittler et al. 2006), suggesting functional conservation of AREB between Arabidopsis and tomato plants in response to stress conditions.

To further confirm the stress response of the SIAREB identified by the microarray system, Northern-blot analysis was performed. To this end, leaves and roots were collected separately from wild-type tomato plants that were subjected to chilling, air drying, and salt stresses for various time periods. A tomato CI7-like dehydrin gene (EST clone cLEX8A20), a homolog of Arabidopsis COR47 (Cold-regulated 47) and potato CI7 (Cold-induced 7) dehydrin (van Berkel et al. 1994), was used to assess the stress treatments of wild-type tomato plants. Dehydrin

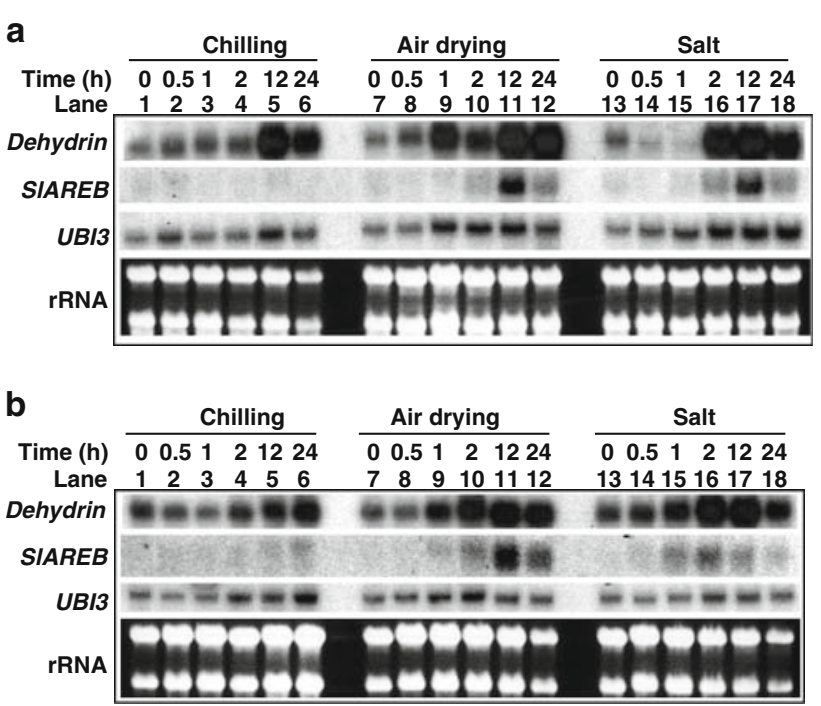

Fig. 1 Tomato transcription factors respond to abiotic stresses. Northern-blot analysis was used to investigate the expression profiles of transcription factors under chilling, air drying, and salt conditions. Wild-type tomato plants were treated with chilling, water deficit, or salt for various times, and leaves (a) and roots (b) were collected separately. Each lane was loaded with $10 \mu \mathrm{g}$ total RNA. Probes used were tomato dehydrin and SIAREB. Tomato UBI3 (ubiquitin 3) and rRNA were used as internal controls

belongs to the LEA (late embryogenesis abundant) protein family and has been previously shown to be induced by salt and ABA in many plant species (Brini et al. 2007; Hundertmark and Hincha 2008). The obtained Northernblot analysis results confirmed that the mRNA of tomato dehydrin rapidly accumulated to high levels in both leaves and roots when wild-type plants were treated with chilling, air drying, and high salinity, indicating that the wild-type plants were suffering from abiotic stresses (Fig. 1).

Northern-blot analysis was used to investigate the SlAREB transcription under stress conditions in leaves as well as in roots (Fig. 1). By air drying, SlAREB was induced at $2 \mathrm{~h}$ and reached a maximum at $12 \mathrm{~h}$ in both leaves and roots (Fig. 1, lanes 10-11). By contrast, in the hydroponic system, the induction of SIAREB expression by salt treatment differed between roots and leaves. Accumulation of SIAREB transcripts was detected $2 \mathrm{~h}$ after salt treatment in leaves and reached a maximum at $12 \mathrm{~h}$ (Fig. 1a, lanes 16-17). In roots, the expression of SIAREB was detected $1 \mathrm{~h}$ after salt treatment, reached its highest level at $2 \mathrm{~h}$, and then gradually declined to background level at $24 \mathrm{~h}$ after salt treatment (Fig. 1b, lanes 15-18). In contrast to air drying and salt treatments, chilling showed no significant effect in the RNA level of SlAREB in either leaves or roots (Fig. 1, lanes 1-6). Thus, the Northern-blot data were consistent with the results obtained through microarray analysis, which showed that SIAREB was transiently upregulated by air drying and high salinity stress in both tomato leaves and roots. 
Fig. 2 The bZIP domain of SIAREB is highly similar to bZIP-containing proteins. Amino acid sequences of tomato SlAREB, Arabidopsis AREB1 and AREB2, Hordeum vulgare HvABI5, Nicotiana tabacum phi-2, and Phaseolus vulgaris bZIP transcription factor 6 (PvbZIP6) were aligned using the ClustalW program and showed conservation of the bZIP domain (underlined). Asterisks indicate putative phosphorylation sites (R-X-X-S/T) for a $42-\mathrm{kDa}$ protein kinase. Identical residues between proteins are marked by dark shading

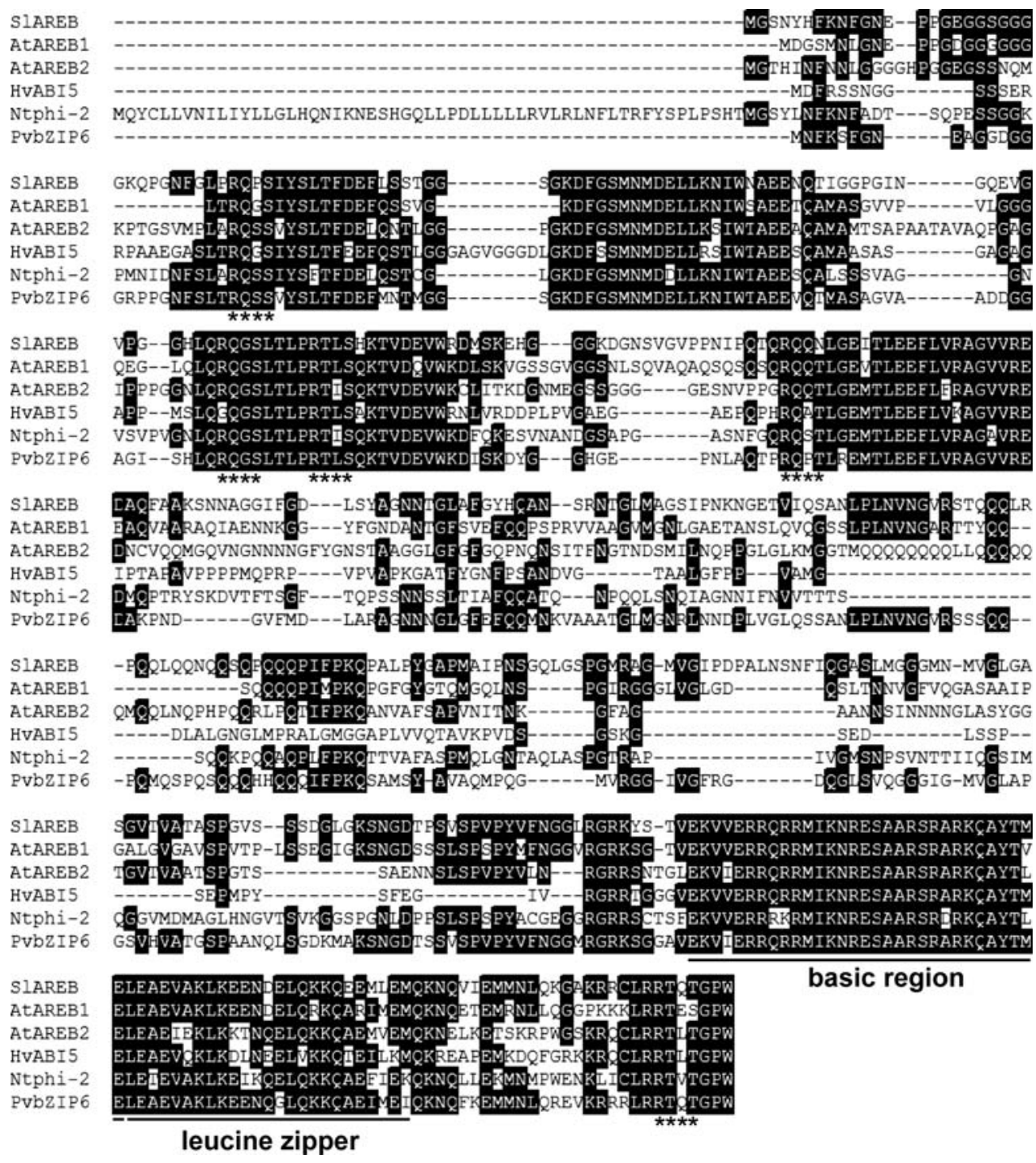

ABA-responsive element binding protein in tomato plants

Among the transcription regulators we identified from the tomato cDNA microarray (Supplementary data 1), the AtAREB1 homolog SIAREB was characterized. Since only a partial cDNA fragment of the EST clone LEPSR08G09 was initially isolated, we used $5^{\prime}$ and $3^{\prime}$ Rapid Amplification of cDNA Ends (RACE, Supplementary material) followed by RT-PCR to obtain the full-length cDNA. Sequence alignments and domain searching revealed that the predicted protein likely belongs to a member of the AREB family, as it shared 50\% identity in amino acid sequences with AREB1 (accession number: BAB12404) and $41 \%$ identity with AREB2 (accession number: BAB12405) in Arabidopsis, as well as 44\% identity with Nicotiana tabacum phi-2 (accession number: BAB61098), and 52\% identity with Phaseolus vulgaris bZIP transcription factor 6 (accession number: AAK39132). Furthermore, the high sequence similarity of this protein with members of the AREB family within the basic and leucine zipper domains, which are highly conserved among various plant species, suggests that LEPSR08G09 is an AREB homolog in tomato plants; it was therefore designated as SIAREB1 (Solanum lycopersicum ABA-responsive element binding protein 1, GenBank accession number AY530758; Yanez et al. 2009) (Fig. 2). It has been reported that an ABAactivated $42-\mathrm{kDa}$ protein kinase activity controls the activation of AtAREB1 by phosphorylation of the Ser/Thr residues of R-X-X-S/T sites in the conserved regions of AtAREB1 (Furihata et al. 2006). Although SlAREB only shared 50\% identity with AtAREB1, five conserved R-X-X-S/T sites were observed in SlAREB (Fig. 2), suggesting that it may be a functional homolog. 
SlAREB protein is able to activate a luciferase reporter driven by ABRE-containing promoter in tomato protoplasts

In Arabidopsis mesophyll protoplasts, AtAREB1 and AtAREB2 transiently activate the expression of the $\beta$-glucuronidase (GUS) reporter gene fused to Arabidopsis RD29A (AtRD29A) and AtRD29B promoters, which contain ABREs (Uno et al. 2000; Narusaka et al. 2003). The AtRD29A promoter has been confirmed to be induced at significant levels by desiccation, cold, high salt conditions, and ABA in both transgenic Arabidopsis and tobacco (Yamaguchi-Shinozaki and Shinozaki 1993). Since SlAREB is an AREB homolog in tomato plants, the AtRD29A promoter was used to examine the activation ability of S1AREB protein in a tomato protoplast system. To this end, an effector plasmid containing the CaMV $35 \mathrm{~S}$ promoter and $\Omega$ enhancer fused to the $S I A R E B$ gene and a reporter plasmid containing the AtRD29A promoter fused to a LUC were employed (Fig. 3a). The AtRD29A promoter alone was slightly activated when protoplasts were treated with ABA (Fig. 3b). After co-transfection of the $S I A R E B$ and AtRD29A constructs into tomato protoplasts, a significantly increased luciferase activity (fivefold), corresponding to increased AtRD29A promoter activity, was observed in the presence of ABA (Fig. 3b). The activation of luciferase activity is ABA-dependent: without exogenous ABA application, SlAREB did not enhance AtRD29A promoter activity as compared to the pUC18 control. It has been reported that $\mathrm{ABA}$-dependent phosphorylation of AtAREB1 is required for its transactivation ability, which is suppressed by the protein kinase inhibitor staurosporine (Uno et al. 2000). However, we only detected about $20 \%$ reduction of ABA-dependent SlAREB transactivation of AtRD29A promoter by staurosporine (Fig. 3b).

To test whether SIAREB protein could activate a tomato ABRE-containing promoter, we used a tomato LAP (SILAP) promoter fused to a luciferase reporter gene for transient expression analysis (Fig. 4a). The promoter region of SILAP gene (Ruiz-Rivero and Prat 1998) contains three ABRE-like cis-elements 'ACGTG': one in the sense strand and two in the antisense strand. Transient expression analysis showed that ABA slightly activated the SILAP promoter in tomato protoplasts, which is consistent with previous results (Chao et al. 1999) (Fig. 4b). Similarly, the SILAP promoter was slightly activated by SIAREB protein in the absence of ABA in tomato protoplasts (Fig. 4b). However, ABA treatment in the presence of the SIAREB construct enhanced the $L A P$ promoter activity significantly (Fig. 4b). Furthermore, the activation of the SLLAP promoter by SIAREB protein in the presence of ABA was

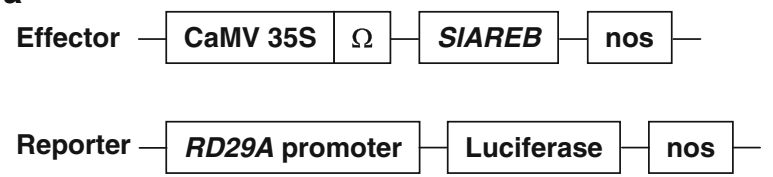

b

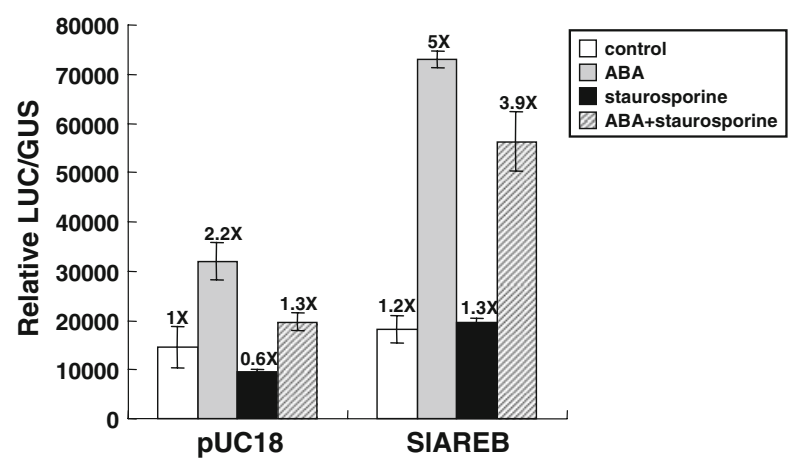

C

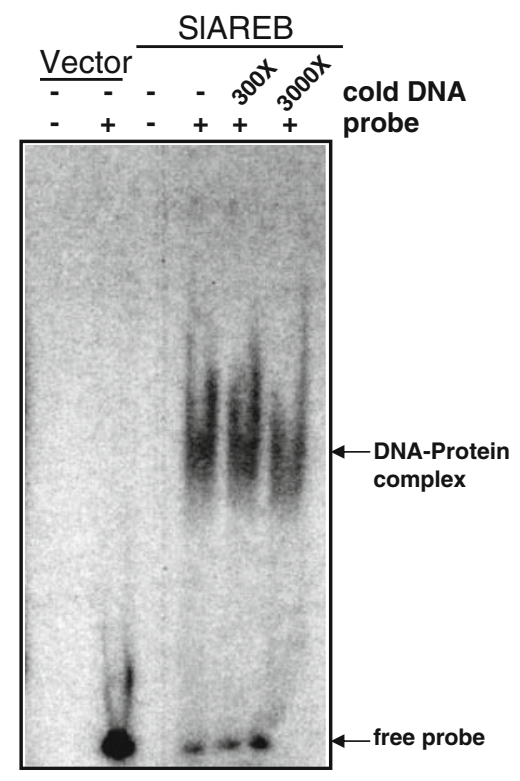

Fig. 3 S1AREB binds and transactivates the AtRD29A promoter, functioning as a transcriptional activator. a An effector plasmid containing SIAREB driven by the CaMV $35 S$ promoter and tobacco mosaic virus (TMV) $\Omega$ enhancer sequence was co-transfected into wild-type tomato protoplasts with a reporter plasmid containing the $A t R D 29 A$ promoter fused to firefly luciferase. b After electroporation, the protoplasts were treated with buffer (control, white bars), ABA (gray bars), staurosporine (black bars) or ABA combined with staurosporine (ABA+ staurosporine, hatched bars) for $40 \mathrm{~h}$. A GUS reporter gene driven by $C a M V 35 S$ promoter in pUC18 plasmid was co-transfected in each experiment to normalize the transfection efficiency. Error bars represent the standard deviation from the mean of triplicate experiments. c Electrophoretic mobility shift assay (EMSA) using a 120-bp-long, radiolabeled fragment probe from the AtRD29A promoter containing $\mathrm{ABRE}$ and $4 \mu \mathrm{g}$ of recombinant proteins. Bacterial proteins carrying an empty vector were used as a binding reaction control. The molar excess of the cold DNA used (300- and 3,000-fold) is indicated at the top of each lane 
a

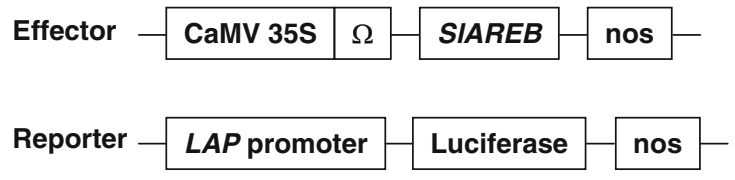

b

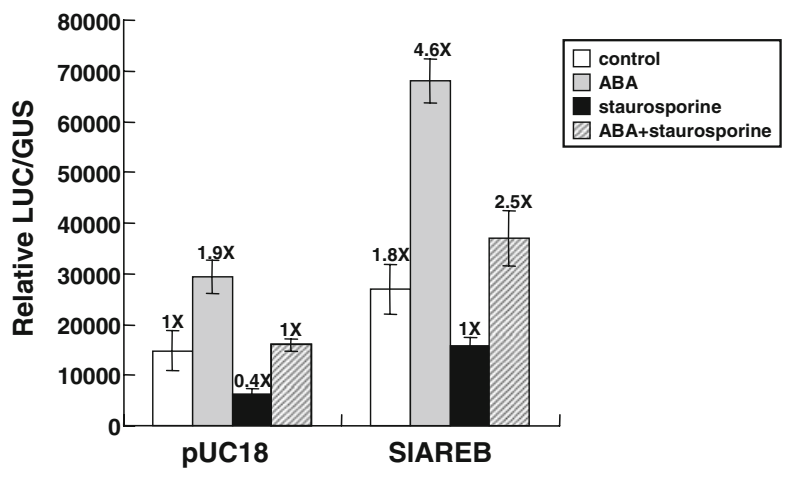

C

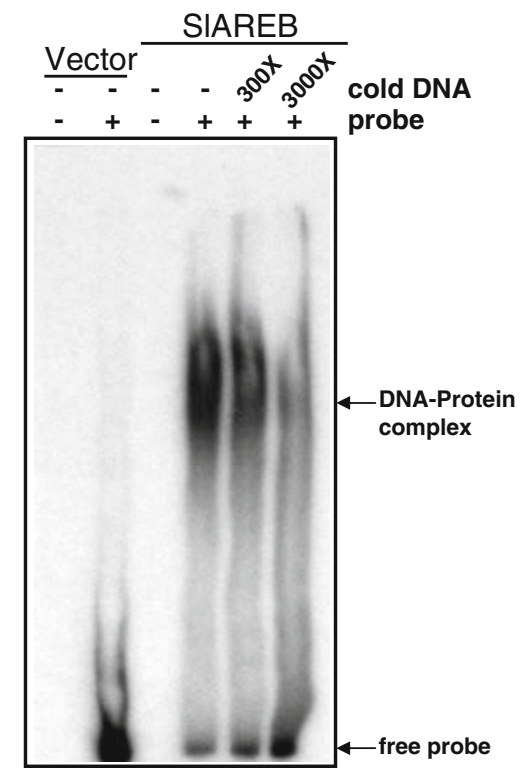

Fig. 4 The binding and transactivation abilities of SIAREB protein to SILAP promoter are revealed by transient expression and EMSA analyses. a An effector plasmid containing SIAREB driven by $\mathrm{CaMV}$ $35 S$ promoter and TMV $\Omega$ sequence was co-transfected into wild-type tomato protoplasts with a reporter plasmid containing the SlLAP promoter fused to firefly luciferase. b After electroporation, the protoplasts were treated with buffer (control, white bars), ABA (gray bars), staurosporine (black bars) or ABA combined with staurosporine (ABA + staurosporine, hatched bars) for $40 \mathrm{~h}$. A GUS reporter gene driven by $C a M V 35 S$ promoter was co-transfected in each experiment to normalize the transfection efficiency. Bars indicate the standard deviation of triplicates. c EMSA using a 150bp-long, radiolabeled fragment probe from the SILAP promoter containing three putative ABREs and $4 \mu \mathrm{g}$ of recombinant proteins. Bacterial proteins with an empty vector were used as binding reaction control. The molar excess of cold DNA used (300- and 3,000-fold) is indicated at the top of each lane largely suppressed by staurosporine (Fig. 4b). Therefore, overproduction of SIAREB alone did not sufficiently activate SILAP and AtRD29A promoter activities (Figs. 3b, 4b). The ABA-enhanced maximum transactivation of AtRD29A and SILAP promoters by SIAREB protein was probably due to post-translational modification, such as phosphorylation, which was repressed by staurosporine (Figs. 3b, 4b).

The DNA-binding domain of SIAREB physically interacts with the promoter regions of $A t R D 29 A$ and SILAP in vitro

As shown in Figs. $3 \mathrm{~b}$ and $4 \mathrm{~b}$, SlAREB protein transactivated AtRD29A and SILAP promoters in ABA-treated tomato protoplasts. To test whether SIAREB protein could bind to AtRD29A and SILAP promoters, we performed electrophoretic mobility shift assays (EMSA) using purified DNA-binding domain of SIAREB as His-tag fusion protein. As shown by a shifted band (Figs. 3c, 4c), the recombinant DNA-binding domain of SIAREB protein bound to the two DNA fragments containing either the AtRD29A or the SILAP promoter. When an excess amount of unlabeled DNA was added, the binding activity was diminished (Figs. 3c, 4c). These results indicate that the DNA-binding domain of SIAREB was able to bind to AtRD29A and SILAP promoters containing ABREs in vitro (Figs. 3c, 4c). In summary, SIAREB has binding ability in vitro and can transactivate AtRD29A and SILAP promoters in vivo.

ABA is essential to activate $A t R D 29 A$ expression in constitutively expressed SIAREB transgenic Arabidopsis

To elucidate the function of SIAREB in plants, we generated 21 transgenic Arabidopsis plants that overexpressed SIAREB cDNA under the control of CaMV $35 S$ promoter (35S::SlAREB). Three $\mathrm{T}_{3}$ independent lines (L40, L74 and L77) with high-level expression of transgene SIAREB were used for further analyses. Ectopically expressed SIAREB transcripts were detected in three transgenic lines but not in wild-type plants (Fig. 5). We did not detect any AtRD29A transcripts in either wild-type plants or the three transgenic lines without exogenous $\mathrm{ABA}$ (time point 0 ), suggesting that SlAREB alone was not sufficient to activate AtRD29A gene expression in the absence of ABA. ABA-induced AtRD29A expression was clearly observed after $\mathrm{ABA}$ treatment for $5 \mathrm{~h}$ in wild-type as well as transgenic plants (Fig. 5). The expression of $A t R D 29 A$ transcripts was enhanced in transgenic tomato plants overexpressing SlAREB after ABA treatment. 


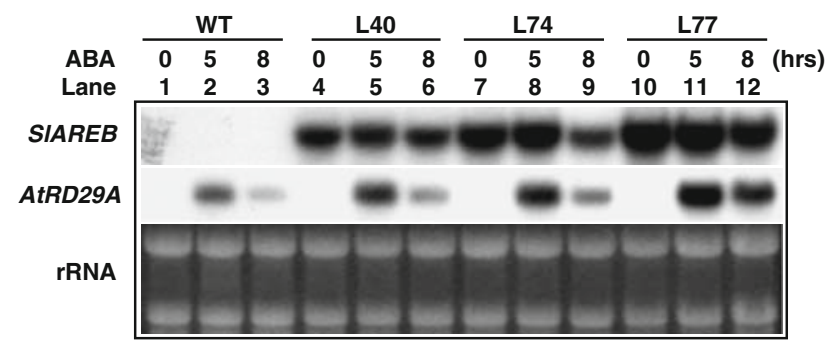

Fig. 5 Overexpression of tomato SIAREB in Arabidopsis plants is insufficient to activate $A t R D 29 A$ expression in the absence of ABA. Three-week-old wild-type (WT) and transgenic plants $\mathrm{T}_{3}$ (L40, L74, L77) were treated with $50 \mu \mathrm{M}$ ABA for 5 and $8 \mathrm{~h}$. Total RNA was extracted, and $10 \mu \mathrm{g}$ RNA was used in Northern-blot analysis using tomato SlAREB and Arabidopsis RD29A as probes. rRNA was used as a loading control

Transgenic Arabidopsis plants overexpressing SIAREB show increased tolerance to water deficit and high salinity stress

It has been reported that overexpression of AtAREB 1 enhances tolerance to multiple stresses, including drought, salt, heat, and oxidative stresses in transgenic plants (Kim et al. 2004; Fujita et al. 2005). To test whether overexpression of SIAREB in Arabidopsis can increase tolerance to abiotic stresses, such as water deficit and high salinity, three independent transgenic lines were subjected to stress treatments. Wild-type plants and three independent transgenic lines were grown in the same pot with regular watering. After withdrawing the water supply for 2 weeks, leaves of wild-type Arabidopsis plants curled and wilted; however, the three transgenic lines grew normally without serious dehydration and flowered later than the wild-type plants (Fig. 6a). To test salt-stress tolerance, wild-type plants and three transgenic lines were grown in hydroponic culture for 3 weeks. After treating with $150 \mathrm{mM} \mathrm{NaCl}$ for 2 weeks, wild-type plant leaves became pale green, while transgenic plant leaves turned dark green (Fig. 6b). In addition, high salinity caused more severe growth retardation in wild-type plants than in transgenic plants (Fig. 6b). In conclusion, ectopically expressed tomato SIAREB in Arabidopsis increased tolerance to water deficit and salt stresses. Consistent with results of transient assays, SlAREB also increased AtRD29A expression in transgenic Arabidopsis plants under ABA treatment (Fig. 5). To clarify whether SIAREB activated other stress-responsive genes that are likely involved in stress tolerance, AtCOR47 was used as a probe to perform Northern-blot analysis. AtCOR47 transcripts accumulated under water deficit and salt stress conditions in wild-type plants as well as transgenic plants (Fig. 6c). We detected more AtCOR47 transcripts in transgenic plants in comparison with wild-type plants upon water deficit and salt treatments (Fig. 6c). Taken together, overexpression of a tomato SIAREB a

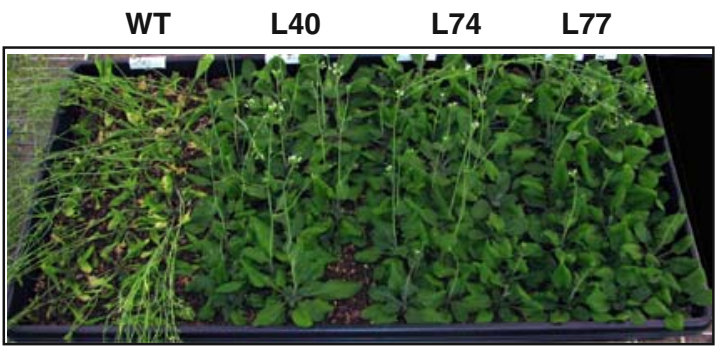

b
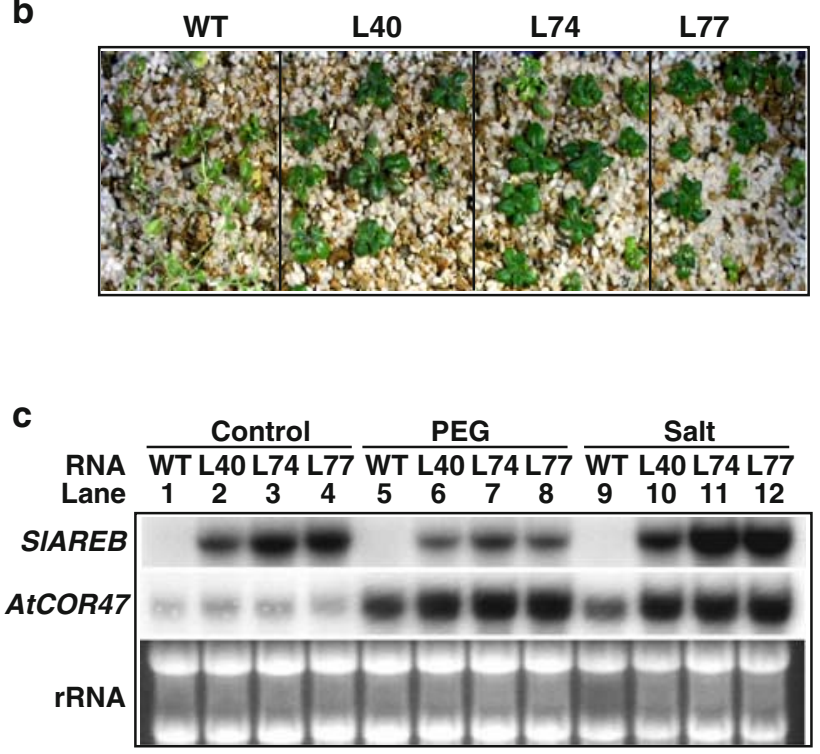

Fig. 6 Ectopically overexpressed tomato SlAREB in Arabidopsis plants enhances water deficit and salt tolerance. a Wild-type (WT) and transgenic plants $\mathrm{T}_{3}(\mathrm{~L} 40, \mathrm{~L} 74, \mathrm{~L} 77)$ were grown in the same pot with regular watering, following water deprivation for 2 weeks. b Threeweek-old wild-type and transgenic plants were treated with $150 \mathrm{mM}$ $\mathrm{NaCl}$ for 2 weeks. c Two-week-old wild-type and transgenic plants were incubated with water (control), 30\% PEG (water deficit treatment), or $300 \mathrm{mM} \mathrm{NaCl}$ (salt treatment) for $5 \mathrm{~h}$. Total RNA was extracted and $10 \mu \mathrm{g}$ RNA was used in Northern-blot analysis using tomato SIAREB and Arabidopsis COR47 as probes. rRNA was used as a loading control

enhanced tolerance to water deficit and salt stresses in transgenic Arabidopsis plants and activated stress-responsive genes such as AtRD29A and AtCOR47.

Overexpression of SlAREB in transgenic tomato plants enhanced tolerance to water deficit and salt stresses

To examine whether SIAREB overexpression in tomato also conferred tolerance to abiotic stresses, we generated SlAREB-overexpressing transgenic tomato plants. After hygromycin selection, we obtained 20 independent $T_{0}$ lines, all of which were confirmed by genomic PCR and Southern-blot analyses (data not shown). The three homozygous $\mathrm{T}_{2}$ lines (LA1, LA2 and LA3) with the highest accumulation of SIAREB transcripts were used for further analyses. As shown in Fig. 7a, Northern-blot 
Fig. 7 Constitutively expressed SIAREB in transgenic tomato plants improves water deficit tolerance. a Northern-blot analysis detected SIAREB and $H p t$ transcripts in three transgenic tomato lines (LA1, LA2 and LA3) but not in wildtype plants $(W T)$ under normal conditions. Probes used were SlAREB, Hpt and Ubiquitin $(U b i)$. b Wild-type and three transgenic $\mathrm{T}_{2}$ plants (WT, LA1, LA2 and LA3) were grown at $24^{\circ} \mathrm{C}$ without watering for 21 days, and then photographs were taken. c Wild-type plants and plants from three transgenic lines were deprived of water for various amounts of time. $\mathrm{Fv} / \mathrm{Fm}$ values were measured on days $0,7,14$, and 21. d During the periods of water deprivation, water content of leaves was measured on days $0,7,14$, and 21. e To measure water content of roots, we sacrificed wild-type plants and plants from three transgenic lines at the end of water-deficit treatment. Water content of roots was measured on days 0 and 21 . Each value is the mean \pm standard deviation of three independent experiments
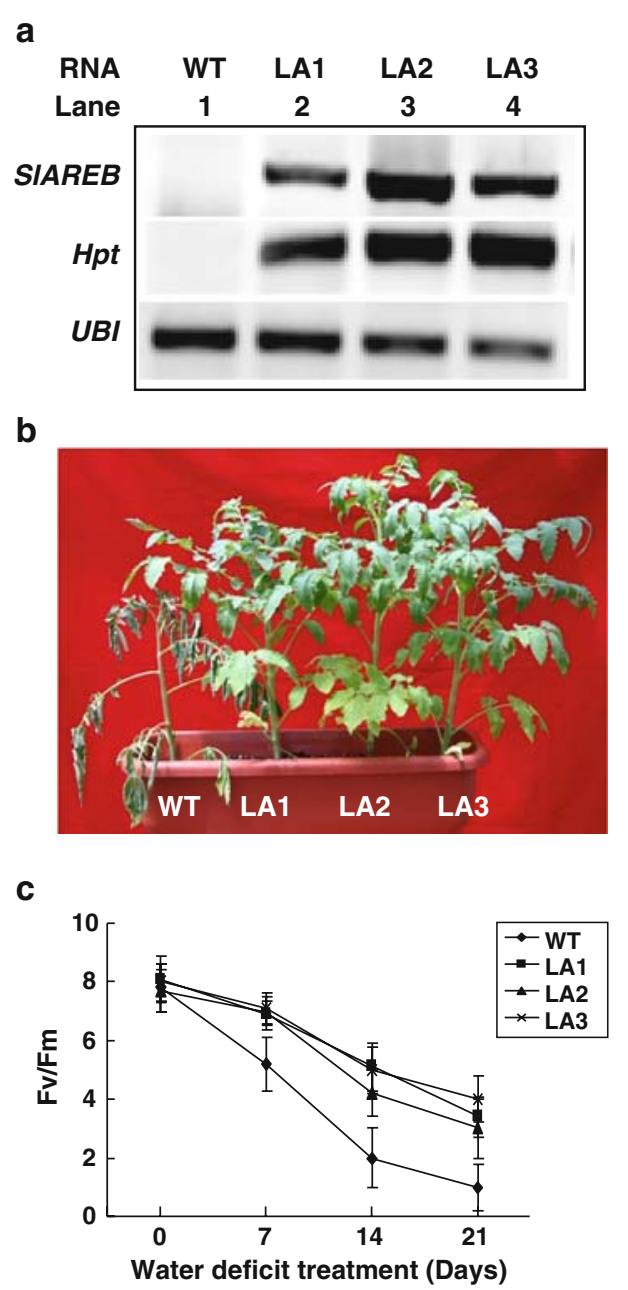
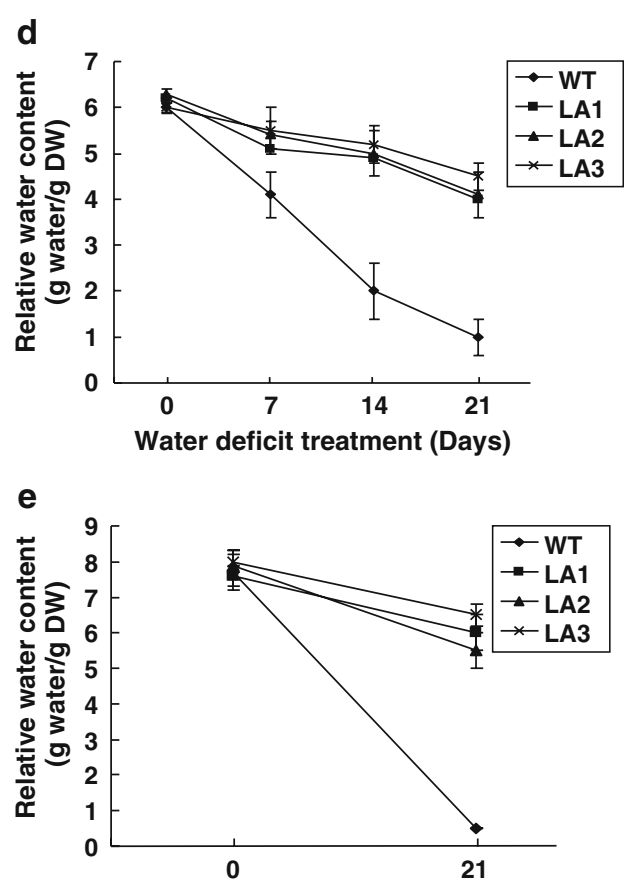

Water deficit treatment (Days) analysis proved that transgenes $S I A R E B$ and $H p t$ are expressed in the transgenic lines, but not in wild-type plants under normal conditions. All of these transgenic plants exhibited normal growth with no deleterious or pleiotropic effects, suggesting that overproduction of $S I A R E B$ did not influence transgenic plant growth or morphological changes.

When transgenic $\left(\mathrm{T}_{2}\right)$ and wild-type tomato plants, which were grown in the same pot, were left unwatered continually for 21 days, the leaves of wild-type plants became wilted and curled, while transgenic plants grew healthily (Fig. 7b). The photosynthesis capacity, measured as chlorophyll fluorescence maximum photochemical efficiency of PSII in the dark-adapted state (Fv/Fm), declined in tandem with the periods of water withdrawal in wildtype plants as well as transgenic plants (Fig. 7c). However, the PSII integrity was significantly higher in transgenic plants than in wild-type plants under water deficit conditions (Fig. 7c). Dehydrated wild-type plants did not recover from water deficit treatment after re-watering, and Fv/Fm values were still low (data not shown). The three transgenic lines maintained $50 \%$ of the photosynthesis activity of well-watered control, even without watering for 21 days (Fig. 7c), and almost completely recovered after watering was resumed (data not shown). In addition, we measured water content in tissues to evaluate the ability of plants to retain water (Fig. 7d, e). Water content in leaves and roots decreased in parallel with periods of water-deficit treatment both in wild-type and transgenic plants (Fig. 7d, e). However, a marked reduction in water content was only observed in wild-type plants. The three transgenic lines retained considerably more water in leaves and roots than wild-type plants during the periods of water-deficit treatment (Fig. 7d, e). Consequently, overproduction of SIAREB significantly confers tolerance to water deficit in transgenic tomato plants.

To determine whether transgenic plants were tolerant to salt stress, we grew transgenic tomato $\left(\mathrm{T}_{2}\right)$ and wild-type plants in the same pot and watered them with $200 \mathrm{mM}$ $\mathrm{NaCl}$ every second day. After watering with salt water for 2-4 weeks, wild-type plants wilted and subsequently died (Fig. 8a). However, the transgenic plants grew healthily and developed fruits at the end of salt treatment. To compare stress injury in wild-type and transgenic plants, 
a

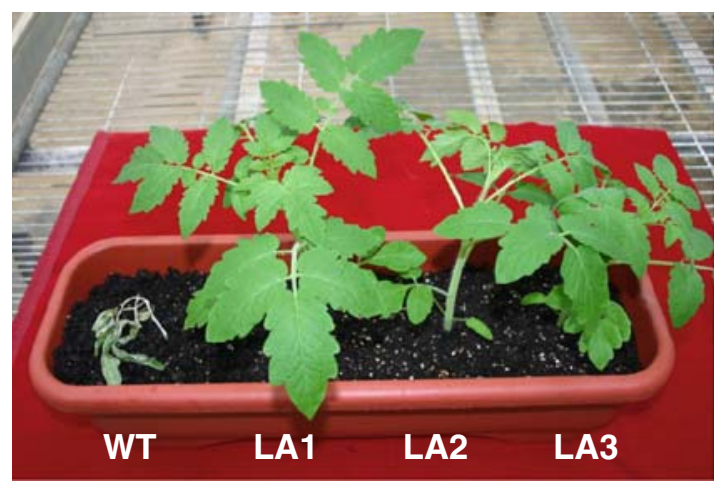

b

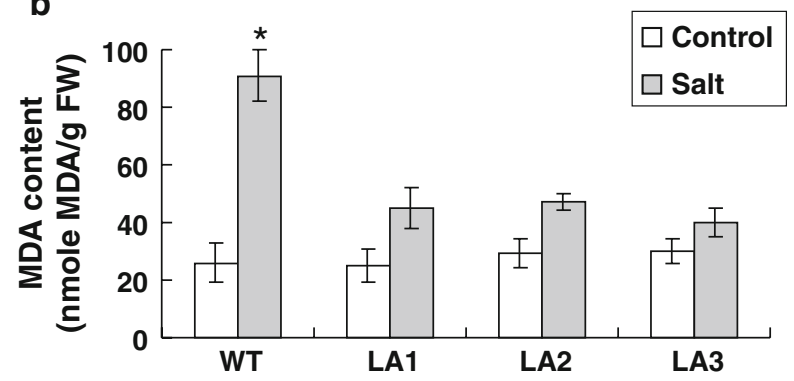

C
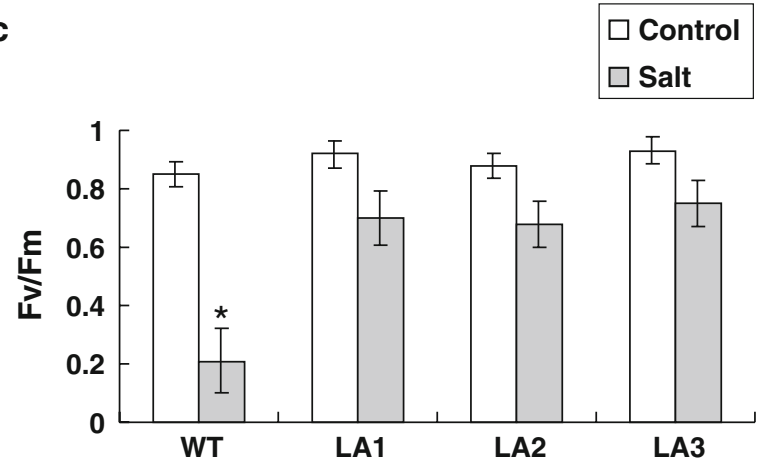

Fig. 8 Overproduction of SIAREB improves salt tolerance in transgenic tomato plants. a Two-week-old wild-type plants and plants from three transgenic lines were watered with $200 \mathrm{mM} \mathrm{NaCl}$ for 4 weeks. At the end of the salt treatment, photographs were taken. b MDA content and Fv/Fm values (c) of salt-treated and non-treated plants were measured at 14th day of the salt treatment. Each value corresponds to the mean \pm standard deviation of three independent experiments

we measured MDA (malonyldialdehyde), an end product of lipid peroxidation that is considered a reliable indicator of membrane injury under stress conditions (Jouve et al. 1993; Zhang and Kirkham 1994). There was no significant difference between MDA content in the three transgenic lines and the wild-type plant under normal conditions (Fig. 8b). At the end of salt treatment, we detected MDA accumulation in wild-type and the three transgenic lines as compared with control treatment (Fig. 8b). The amount of MDA accumulated in transgenic plants, though, was about half of the amount determined in wild-type plants after salt treatment for 2 weeks (Fig. 8b). Thus, membranes were

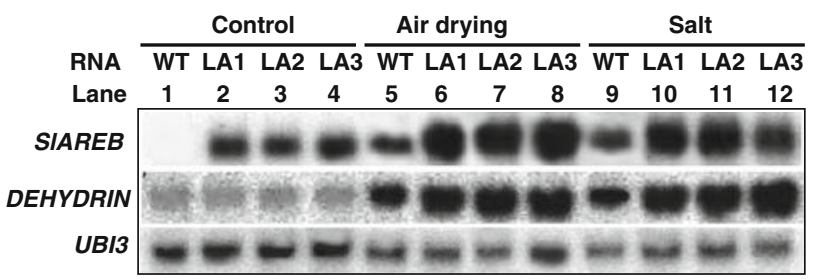

Fig. 9 SIAREB correlates with to dehydrin expression under water deficit and high salinity conditions. Wild-type plants (WT) and plants from three transgenic lines (LA1, LA2 and LA3) were subjected to air-drying treatment for 21 days or salt treatment $(200 \mathrm{mM} \mathrm{NaCl})$ for 1 month. Northern-blot analysis was then performed using SIAREB and dehydrin as probes. Tomato ubiquitin 3 (UBI3) was used as an internal control

severely damaged in wild-type plants, whereas transgenic plants maintained membrane integrity during salt treatment. In addition, salt treatment had harsh effects on photosynthesis activity in wild-type plants as shown by $\mathrm{Fv} / \mathrm{Fm}$ values, whereas there was only a moderate decline in photosynthesis capacity in transgenic plants during salt treatment (Fig. 8c). We conclude that constitutively expressed SIAREB confers salt tolerance to transgenic tomato plants.

Dehydrin gene expression is correlated to SIAREB transgene in transgenic tomato under stress conditions

To investigate whether stress-related genes were upregulated in SIAREB transgenic tomato plants, we used a tomato CI7-like dehydrin cDNA as a probe to perform Northern-blot analysis (Fig. 9). Tomato dehydrin transcripts accumulated drastically in wild-type plants as well as the three transgenic lines under water deficit and high salinity conditions (Fig. 9); however, much higher amounts of dehydrin transcripts were detected in the three transgenic lines than in wild-type plants under water deficit and high salinity conditions (Fig. 9). Under normal conditions, SIAREB transcripts were only detected in the three transgenic lines. Under water deficit and saline treatments, considerably higher quantities of SIAREB transcripts accumulated in both wild-type and transgenic plants (Fig. 9). Thus, dehydrin is induced by water deficit and salt stress and the amount of induction seems to be correlated to SIAREB transgene expression.

Transactivation of SIAREB on tomato dehydrin promoter depends on ABA signaling

To verify whether SIAREB protein could directly upregulate dehydrin gene expression under stress conditions, an 1172-bp-long sequence encompassing the tomato CI7-like dehydrin promoter (SlCI7pro) was isolated by Genome Walking. As shown in Supplementary Fig. S1, SlCI7pro 
contains two ABRE-like elements in the sense strand and four ABRE like elements in the complementary strand. For transient expression analysis, a reporter plasmid was constructed by fusing SlCI7pro to a luciferase reporter gene (Fig. 10a). After co-transfection of this reporter and the SIAREB effector constructs into tomato suspension protoplasts, dehydrin promoter activity, as assessed by luciferase activity, increased $40 \%$ with ABA treatment (Fig. 10b). Overproduction of S1AREB alone did not affect dehydrin promoter activity. ABA-enhanced transactivation of tomato dehydrin promoter may also be caused by posttranslational modifications of SlAREB, as described above.

\section{Discussion}

Stress-responsive transcriptional regulators are identified and characterized from a tomato microarray

Microarray-based transcriptome analysis provides a powerful tool for global transcription profiling and discovery of
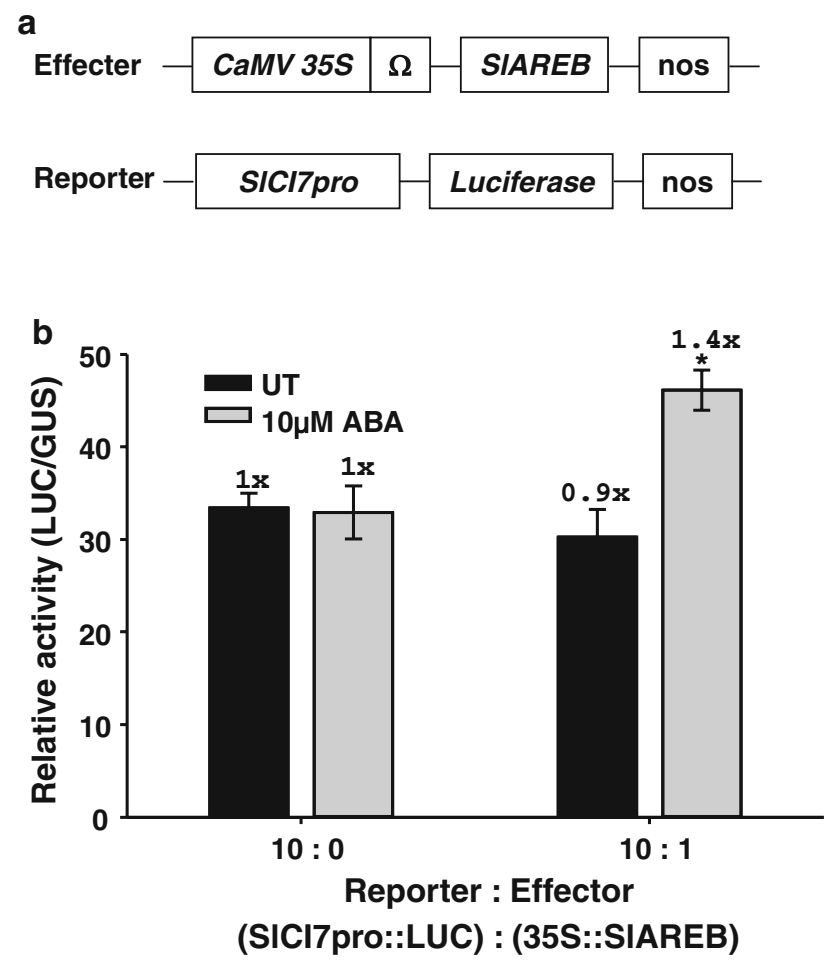

Fig. 10 SIAREB binds and transactivates tomato CI7-like dehydrin promoter. a An effector plasmid containing SlAREB driven by the CaMV $35 S$ promoter and TMV $\Omega$ sequence was co-transfected into wild-type tomato protoplasts with a reporter plasmid containing the SlCI7-like dehydrin promoter (SlCI7pro) fused to firefly luciferase (LUC). b After electroporation, the protoplasts were treated with buffer $(U T)$ or ABA for $20 \mathrm{~h}$. GUS reporter gene driven by CaMV $35 \mathrm{~S}$ promoter was co-transfected in each experiment to normalize the transfection efficiency. Bars indicate the standard deviation of triplicates transcription regulators and stress-responsive genes not only in Arabidopsis but also in crop and tree improvement (Douglas and Ehlting 2005). Large-scale transcriptional responses to abiotic stresses in tomato have not been documented previously, although small-scale studies have been conducted on light signaling, fruit development and composition, fruit ripening, and disease resistance (Fei et al. 2004; Alba et al. 2005; Balaji et al. 2007; Mounet et al. 2009; Rutitzky et al. 2009). Transcription profiling of these transcription factors facilitates the understanding of their functions in plants and complex regulatory interactions induced by stress at the transcriptional level in tomato plants. Living organisms require numerous transcriptional regulators to control complex and diverse biological processes or to adapt to environmental stimuli. Several transcription factors, including AP2/ERF, C2H2, and bZIP families, have been identified from tomato cDNA microarray (Liu et al. 2006 and Chan, unpublished data). This information will be important for revealing the functions of these transcription regulators and facilitating the study of signal transduction and gene regulation of tomato plants under various stresses. In addition, these transcription factors will contribute to the generation of transgenic plants against various stresses. Here, we characterized a bZIP transcription factor gene, SIAREB that increases its activity significantly under air-drying and high salinity conditions in tomato (Fig. 1). The Arabidopsis homolog of SlAREB is $A R E B 1$, which is a well-known transcription regulator in the ABA-mediated stress signal transduction pathway (Uno et al. 2000). bZIP proteins characteristically contain a highly conserved bZIP domain, which is composed of a basic region for sequence-specific DNA binding and a leucine zipper for dimerization specificity (Nijhawan et al. 2008). Genetic and molecular studies suggest that bZIP transcription factors function in seed maturation and germination, ABA and/or stress signaling, and defense and photomorphogenesis (Jakoby et al. 2002; Lopez-Molina et al. 2002; Zhang et al. 2003; Fujita et al. 2005; Thurow et al. 2005; Mallappa et al. 2006; Nijhawan et al. 2008).

Tomato SIAREB functions as a transcriptional activator to regulate stress-related gene expression under stress conditions and ABA treatment

SIAREB shows high conservation of the basic and leucine zipper regions and phosphorylation sites $\mathrm{R}-\mathrm{X}-\mathrm{X}-\mathrm{S} / \mathrm{T}$ in comparison with Arabidopsis AREB1 and AREB2 (Fig. 2). It has been reported that an ABA-activated 42-kDa kinase phosphorylates Ser/Thr residues in the conserved R-X-X-S/T sites of AREB1, whose transactivation activity is suppressed by substitution of one Ser/Thr into Ala (Furihata et al. 2006). SnRK2.2 and SnRK2.3 are considered to regulate ABA signaling through phosphorylation of 
AREBs, after which phosphorylated AREBs activate ABRE-dependent gene expression (Yoshida et al. 2002; Fujii and Zhu 2009). In addition, ABA-dependent phosphorylation is required for AREB1 and AREB2 to reach maximal activities and activate downstream gene transcription, which is suppressed by the protein kinase inhibitor staurosporine (Uno et al. 2000). Here, we also show evidence that phosphorylation is likely required for SIAREB to activate AtRD29A and SILAP promoter in the presence of ABA treatment, as staurosporine treatment repressed the promoter activity (Figs. 3b, 4b). Since SIAREB transcription factor may require phosphorylation to transactivate downstream genes, we manufactured a recombinant protein containing the SIAREB DNA-binding domain for gel retardation assay to avoid structural or functional disturbance caused by translational modifications. We verified that the DNA-binding domain of SIAREB protein is able to bind to the AtRD29A and SILAP promoter regions, which contain ABREs (Figs. 3c, 4c). Thus, tomato $S I A R E B$ is a functional homolog of Arabidopsis AREB. Constitutively overexpressed AREB1 in Arabidopsis is insufficient to activate downstream gene $A t R D 29 B$ expression under normal conditions (Fujita et al. 2005). However, substitution of Ser/Thr residues to Asp in $\mathrm{R}-\mathrm{X}-\mathrm{X}-\mathrm{S} / \mathrm{T}$ sites results in a phosphorylated, transcriptionally active form of AREB 1 and consequently activates $L E A$-class gene expression without ABA treatment (Fujita et al. 2005; Furihata et al. 2006). These LEA-class genes contain ABREs in their promoter regions (Furihata et al. 2006). In ABA-treated tomato protoplasts, SlAREB is able to transactivate AtRD29A and SILAP promoters, which contain ABRE (Figs. 3b, 4b). Overproduction of SIAREB is not sufficient to activate expression of stress-related genes such as AtRD29A and AtCOR47 in Arabidopsis or SlCI7like dehydrin in tomato plants under normal conditions (Figs. 5, 6, 9). However, ectopically expressed SlAREB can activate AtRD29A expression under ABA treatment, in agreement with the data obtained in the transient assays (Figs. 3b, 5), whereas the AtCOR47 gene is moderately activated under stress treatments (Fig. 6c). The stressrelated gene dehydrin is correlated with overexpressed $S I A R E B$ in transgenic tomato plants under water deficit and salt conditions (Fig. 9). It has been reported that overproduction of multiple dehydrins increases tolerance to freezing and salt stress in Arabidopsis (Puhakainen et al. 2004; Brini et al. 2007). A wealth of evidence indicates that dehydrins may help to stabilize membranes and macromolecules, maintain enzyme activities, and prevent structural damage during dehydration (Close 1996; Rinne et al. 1999). Activation of stress-responsive genes such as AtRD29A, AtCOR47, and SlCI7-like dehydrin by SIAREB may play important roles in increasing water deficit and salt tolerance in transgenic plants (Figs. 5, 6, 7, 8, 9). In summary, SlAREB has the ability to activate some stressrelated gene expression in the presence of exogenous ABA or under stress conditions that trigger the production of ABA, which in turn induces various ABA-responsive genes or indirectly activates SlAREB through phosphorylation by ABA-activated protein kinases. All of these results demonstrate that SIAREB functions as a transcriptional activator in the expression of stress-related genes and plays a vital role in stress responses. It is reported that several ABA-activated SNF1-related protein kinase 2s (SnRK2s) can phosphorylate AREB polypeptides in vitro, and three SnRK2 (SRK2D/E/I) can co-localize and interact with AREB1 in nuclei in Arabidopsis (Fujita et al. 2009). However, the putative tomato protein kinases that participate in phosphorylation of tomato AREB under abiotic stresses have yet to be determined.

Drought and soil salinity are major stresses that adversely affect crop productivity and quality, and thus ways to improve stress tolerance of crop plants are highly warranted. Expanding the knowledge of gene regulation under stress conditions helps us to understand the adaptation and acclimation mechanisms of plants against stresses at the transcriptional level. In this study, SlAREB shows water deficit and salt responsiveness (Fig. 1) implying that it may be involved in the regulation of stress genes and in the improvement of the stress tolerance of plants. Here, we show evidence that overproduced SIAREB enhances tolerance to water deficit and salt stresses both in Arabidopsis and tomato plants (Figs. 6, 7, 8). Under stress conditions, transgenic but not wild-type tomato plants are able to maintain photosynthesis, membrane integrity, and water content (Figs. 7, 8). In fact, it has been reported that $A R E B 1$ increases multiple stress tolerance in transgenic Arabidopsis (Kim et al. 2004; Fujita et al. 2005). Wheat Wabi5, as a counterpart of AREB/ABF, improves abiotic stress tolerance against freezing, osmotic and salt stresses in transgenic tobacco plants (Kobayashi et al. 2008). Our study is the first to report that $A R E B 1$ homolog, a tomato SlAREB1, confers water deficit and salt tolerance not only in Arabidopsis but also in tomato plants. In addition, because the phosphorylation activation of SIAREB protein requires $\mathrm{ABA}$ or abiotic stress treatment, the phenotype and yields of S1AREB transgenic tomato plants showed no significant differences to wild-type plants, indicating a drastic improvement from model plants in the laboratory to crop plants in the fields.

Acknowledgments We appreciate the efforts of Wei-Chou Houng, Ho-Ming Chen, Pei-Wen Cheng, Chi-Jia Peng, Jung-Pin Wu, and the Bioinformatics Core Laboratory of Agricultural Biotechnology Research Center in array printing and establishment of the database. We thank Dr. Su-Chiung Fang (Academia Sinica Biotechnology Center in Southern Taiwan) for helpful discussions and grammar correction. Tsai-Hung Hsieh, Chia-Wen Li, and Ruey-Chih Su 
contributed equally to this work. This research was supported by Academia Sinica, and grants NSC-92-2311-B-001-071 and NSC-952311-B-001-003 from the National Science Council of the Republic of China.

\section{References}

Alba R, Payton P, Fei Z, McQuinn R, Debbie P, Martin GB, Tanksley SD, Giovannoni JJ (2005) Transcriptome and selected metabolite analyses reveal multiple points of ethylene control during tomato fruit development. Plant Cell 17:2954-2965

Balaji V, Gibly A, Debbie P, Sessa G (2007) Transcriptional analysis of the tomato resistance response triggered by recognition of the Xanthomonas type III effecter AvrXv3. Funct Integr Genomics 7:305-316

Brini F, Hanin M, Lumbreras V, Amara I, Khoudi H, Hassairi A, Pages M, Masmoudi K (2007) Overexpression of wheat dehydrin DHN-5 enhances tolerance to salt and osmotic stress in Arabidopsis thaliana. Plant Cell Rep 26:2017-2026

Casaretto JA, Ho T-HD (2005) Transcriptional regulation by abscisic acid in barley (Hordeum vulgare L.) seeds involves autoregulation of the transcription factor HvABI5. Plant Mol Biol 57:21-34

Chao WS, Gu YQ, Pautot VV, Bray EA, Walling LL (1999) Leucine aminopeptidase RNAs, proteins, and activities increase in response to water deficit, salinity, and the wound signals systemin, methyl jasmonate, and abscisic acid. Plant Physiol 120:979-992

Chaves MM, Maroco JP, Pereira JS (2003) Understanding plant responses to drought-from genes to the whole plant. Funct Plant Biol 30:239-264

Chinnusamy V, Schumaker K, Zhu JK (2004) Molecular genetic perspectives on cross-talk and specificity in abiotic stress signalling in plants. J Exp Bot 55:225-236

Close TJ (1996) Dehydrins: Emergence of a biochemical role of a family of plant dehydration proteins. Physiol Plant 97:795-803

Douglas CJ, Ehlting J (2005) Arabidopsis thaliana full genome longmer microarrays: a powerful gene discovery tool for agriculture and forestry. Transgenic Res 14:551-561

Fei Z, Tang X, Alba RM, White JA, Ronning CM, Martin GB, Tanksley SD, Giovannoni JJ (2004) Comprehensive EST analysis of tomato and comparative genomics of fruit ripening. Plant J 40:47-59

Fujii H, Zhu JK (2009) Arabidopsis mutant deficient in 3 abscisic acidactivated protein kinases reveals critical roles in growth, reproduction, and stress. Proc Natl Acad Sci USA 106:8380-8385

Fujita Y, Fujita M, Satoh R, Maruyama K, Parvez MM, Seki M, Hiratsu K, Ohme-Takagi M, Shinozaki K, Yamaguchi-Shinozaki K (2005) AREB1 Is a transcription activator of novel ABREdependent ABA signaling that enhances drought Stress tolerance in Arabidopsis. Plant Cell 17:3470-3488

Fujita Y, Nakashima K, Yoshida T, Katagiri T, Kidokoro S, Kanamori N, Umezawa T, Fujita M, Maruyama K, Ishiyama K, Kobayashi M, Nakasone S, Yamada K, Ito T, Shinozaki K, YamaguchiShinozaki K (2009) Three SnRK2 protein kinases are the main positive regulators of abscisic acid signaling in response to water stress in Arabidopsis. Plant Cell Physiol 50:2123-2132

Furihata T, Maruyama K, Fujita Y, Umezawa T, Yoshida R, Shinozaki K, Yamaguchi-Shinozaki K (2006) Abscisic acid-dependent multisite phosphorylation regulates the activity of a transcription activator AREB1. Proc Natl Acad Sci USA 103:1988-1993

Hobo T, Kowyama Y, Hattori T (1999) A bZIP factor, TRAB1, interacts with VP1 and mediates abscisic acid-induced transcription. Proc Natl Acad Sci USA 96:15348-15353
Hsieh TH, Lee JT, Yang PT, Chiu LH, Yy Charng, Wang YC, Chan MT (2002) Heterologous expression of the Arabidopsis C-repeat/Dehydration response element binding factor 1 gene confers elevated tolerance to chilling and oxidative stresses in transgenic tomato. Plant Physiol 129:1086-1094

Hundertmark M, Hincha DK (2008) LEA (late embryogenesis abundant) proteins and their encoding genes in Arabidopsis thaliana. BMC Genomics 9:118

Jakoby M, Weisshaar B, Droge-Laser W, Vicente-Carbajosa J, Tiedemann J, Kroj T, Parcy F (2002) bZIP transcription factors in Arabidopsis. Trends Plant Sci 7:106-111

Jouve L, Engelmann F, Noirot M, Charrier A (1993) Evaluation of biochemical markers (sugar, proline, malonedialdehyde and ethylene) for cold sensitivity in microcuttings of two coffee species. Plant Sci 91:109-116

Kawasaki S, Borchert C, Deyholos M, Wang H, Brazille S, Kawai K, Galbraith D, Bohnert HJ (2001) Gene expression profiles during the initial phase of salt stress in rice. Plant Cell 13:889-905

Kim S, Kang J-y, Cho D-I, Park JH, Kim SY (2004) ABF2, an ABREbinding bZIP factor, is an essential component of glucose signaling and its overexpression affects multiple stress tolerance. Plant J 40:75-87

Kobayashi F, Maeta E, Terashima A, Takumi S (2008) Positive role of a wheat $H v A B I 5$ ortholog in abiotic stress response of seedlings. Physiol Plant 134:74-86

Kreps JA, Wu Y, Chang HS, Zhu T, Wang X, Harper JF (2002) Transcriptome changes for Arabidopsis in response to salt, osmotic, and cold stress. Plant Physiol 130:2129-2141

Liu N-Y, Ko S-S, Yeh K-C, Charng Y-Y (2006) Isolation and characterization of tomato Hsa32 encoding a novel heat-shock protein. Plant Sci 170:976-985

Lopez-Molina L, Mongrand S, McLachlin DT, Chait BT, Chua NH (2002) ABI5 acts downstream of ABI3 to execute an ABAdependent growth arrest during germination. Plant J 32:317-328

Luehrsen KR, de Wet J, Walbot V (1992) Transient expression analysis in plants using firefly luciferase reporter gene. Methods Enzymol 216:397-441

Mallappa C, Yadav V, Negi P, Chattopadhyay S (2006) A basic leucine zipper transcription factor, G-box-binding factor 1, regulates blue light-mediated photomorphogenic growth in Arabidopsis. J Biol Chem 281:22190-22199

Mittler R, Kim Y, Song L, Coutu J, Coutu A, Ciftci-Yilmaz S, Lee H, Stevenson B, Zhu JK (2006) Gain- and loss-of-function mutations in Zat10 enhance the tolerance of plants to abiotic stress. FEBS Lett 580:6537-6542

Mounet F, Moing A, Garcia V, Petit J, Maucourt M, Deborde C, Bernillon S, Le Gall G, Colquhoun I, Defernez M, Giraudel JL, Rolin D, Rothan C, Lemaire-Chamley M (2009) Gene and metabolite regulatory network analysis of early developing fruit tissues highlights new candidate genes for the control of tomato fruit composition and development. Plant Physiol 149:1505-1528

Mueller LA, Tanksley SD, Giovannoni JJ, van Eck J, Stack S, Choi D, Kim BD, Chen MS, Cheng ZK, Li CY, Ling HQ, Xue YB, Seymour G, Bishop Gerard, Bryan G, Sharma R, Khurana J, Tyagi A, Chattopadhyay D, Singh NK, Stiekema W, Lindhout P, Jesse T, Lankhorst RK, Bouzayen M, Shibata D, Tabata S, Granell A, Botella MA, Giuliano G, Frusciante L, Causse M, Zamir D (2005) The tomato sequencing project, the first cornerstone of the international Solanaceae project (SOL). Comp Funct Genomics 6:153-158

Murashige T, Skoog F (1962) A revised medium for rapid growth and bioassays with tobacco tissue cultures. Physiol Plant 15:473-497

Murray MG, Thompson WF (1980) Rapid isolation of high molecular weight plant DNA. Nucleic Acids Res 8:4321-4325

Narusaka Y, Nakashima K, Shinwari ZK, Sakuma Y, Furihata T, Abe H, Narusaka M, Shinozaki K, Yamaguchi-Shinozaki K (2003) 
Interaction between two cis-acting elements, ABRE and DRE, in ABA-dependent expression of Arabidopsis RD29A gene in response to dehydration and high-salinity stresses. Plant $\mathbf{J}$ 34:137-148

Nijhawan A, Jain M, Tyagi AK, Khurana JP (2008) Genomic survey and gene expression analysis of the basic leucine zipper transcription factor family in rice. Plant Physiol 146:333-350

Oztur ZN, Talame V, Deyholos M, Michalowski CB, Galbraith DW, Gozukirmizi N, Tuberosa R, Bohnert HJ (2002) Monitoring large-scale changes in transcript abundance in drought- and saltstressed barley. Plant Mol Biol 48:551-573

Puhakainen T, Hess MW, Makela P, Svensson J, Heino P, Palva ET (2004) Overexpression of multiple dehydrin genes enhances tolerance to freezing stress in Arabidopsis. Plant Mol Biol 54:743-753

Rabbani MA, Maruyama K, Abe H, Khan MA, Katsura K, Ito Y, Yoshiwara K, Seki M, Shinozaki K, Yamaguchi-Shinozaki K (2003) Monitoring expression profiles of rice genes under cold, drought, and high-salinity stresses and abscisic acid application using cDNA microarray and RNA gel-blot analyses. Plant Physiol 133:1755-1767

Rensink WA, Buell CR (2005) Microarray expression profiling resources for plant genomics. Trends Plant Sci 10:603-609

Rinne PLH, Kaikuranta PLM, van der Plas LHW, van der Schoot C (1999) Dehydrins in cold-acclimated apices of birch (Betula pubescens Ehrh.): production, localization and potential role in rescuing enzyme function during dehydration. Planta 209:377-388

Ruiz-Rivero OJ, Prat S (1998) A -308 deletion of the tomato LAP promoters is able to direct flower-specific and MeJA-induced expression in transgenic plants. Plant Mol Biol 36:639-648

Rutitzky M, Ghiglione HO, Cura JA, Casal JJ, Yanovsky MJ (2009) Comparative genomic analysis of light-regulated transcripts in the Solanaceae. BMC Genomics 10:60

Sakamoto H, Araki T, Meshi T, Iwabuchi M (2000) Expression of a subset of the Arabidopsis $\mathrm{Cys}_{2} / \mathrm{His}_{2}$-type zinc-finger protein gene family under water stress. Gene 248:23-32

Sanjaya, Hsiao PY, Su RC, Ko SS, Tong CG, Yang RY, Chan MT (2008) Overexpression of Arabidopsis thaliana tryptophan synthase beta 1 (AtTSB1) in Arabidopsis and tomato confers tolerance to cadmium stress. Plant Cell Environ 31:1074-1085

Seki M, Satou M, Sakurai T, Akiyama K, Iida K, Ishida J, Nakajima M, Enju A, Narusaka M, Fujita M, Oono Y, Kamei A, Yamaguchi-Shinozaki K, Shinozaki K (2004) RIKEN Arabidopsis full-length (RAFL) cDNA and its applications for expression profiling under abiotic stress conditions. J Exp Bot 55:213-223

Shinozaki K, Yamaguchi-Shinozaki K (2000) Molecular responses to dehydration and low temperature: differences and cross-talk between two stress signaling pathways. Curr Opin Plant Biol 3:217-223

Smith DR (1996) Random primed ${ }^{32}$ P-labeling of DNA. Methods Mol Biol 58:27-29

Stracke R, Werber M, Weisshaar B (2001) The R2R3-MYB gene family in Arabidopsis thaliana. Curr Opin Plant Biol 4:447-456

Takahashi S, Seki M, Ishida J, Satou M, Sakurai T, Narusaka M, Kamiya A, Nakajima M, Enju A, Akiyama K, YamaguchiShinozaki K, Shinozaki K (2004) Monitoring the expression profiles of genes induced by hyperosmotic, high salinity, and oxidative stress and abscisic acid treatment in Arabidopsis cell culture using a full-length cDNA microarray. Plant Mol Biol 56:29-55

Thurow C, Schiermeyer A, Krawczyk S, Butterbrodt T, Nickolov K, Gatz C (2005) Tobacco bZIP transcription factor TGA2.2 and related factor TGA2.1 have distinct roles in plant defense responses and plant development. Plant J 44:100-113

Uno Y, Furihata T, Abe H, Yoshida R, Shinozaki K, YamaguchiShinozaki K (2000) Arabidopsis basic leucine zipper transcription factors involved in an abscisic acid-dependent signal transduction pathway under drought and high-salinity conditions. Proc Natl Acad Sci USA 97:11632-11637

van Berkel J, Salamini F, Gebhardt C (1994) Transcripts accumulating during cold storage of potato (Solanum tuberosum L.) tubers are sequence related to stress-responsive genes. Plant Physiol $104: 445-452$

Yale J, Bohnert HJ (2001) Transcript expression in Saccharomyces cerevisiae at high salinity. J Biol Chem 276:15996-16007

Yamaguchi-Shinozaki K, Shinozaki K (1993) Characterization of the expression of a desiccation-responsive rd29 gene of Arabidopsis thaliana and analysis of its promoter in transgenic plants. Mol Gen Genet 236:331-340

Yanez M, Caceres S, Orellana S, Bastias A, Verdugo I, Ruiz-Lara S, Casaretto JA (2009) An abiotic stress-responsive bZIP transcription factor from wild and cultivated tomatoes regulates stress-related genes. Plant Cell Rep 28:1497-1507

Yoshida R, Hobo T, Ichimura K, Mizoguchi T, Takahashi F, Aronso J, Ecker JR, Shinozaki K (2002) ABA-activated SnRK2 protein kinase is required for dehydration stress signaling in Arabidopsis. Plant Cell Physiol 43:1473-1483

Zhang J, Kirkham MB (1994) Drought-stress-induced changes in activities of superoxide dismutase, catalase, and peroxidase in wheat species. Plant Cell Physiol 35:785-791

Zhang Y, Tessaro MJ, Lassner M, Li X (2003) Knockout analysis of Arabidopsis transcription factors TGA2, TGA5, and TGA6 reveals their redundant and essential roles in systemic acquired resistance. Plant Cell 15:2647-2653

Zhu JK (2001) Plant salt tolerance. Trends Plant Sci 6:66-71 